\title{
ANALISIS PENGGUNAAN RODHAMIN B PADA PRODUK TERASI YANG ADA DISEKITAR MASYARAKAT KECAMATAN POLEANG TENGAH KABUPATEN BOMBANA, SULAWESI TENGGARA
}

Analysis of the use of Rodhamin B in Shrimp Paste Products Around the Community, Poleang Tengah District, Bombana Regency, Southeast Sulawesi

\author{
Aminarti¹, Moh. Nuh Ibrahim ${ }^{1}$, Muh. Syukri Sadimantara ${ }^{2}$ \\ 1Jurusan Teknologi Hasil Perikanan, Fakultas Perikanan dan Ilmu Kelautan Universitas Halu Oleo, Kendari, \\ Sulawesi Tenggara, Indonesia \\ 2Jurusan IImu dan Teknologi Pangan, Fakultas Pertanian Universitas Halu Oleo, Kendari, Sulawesi Tenggara, \\ Indonesia \\ *Email korespondensi: aminarti1997@gmail.com (Telp: +082290207177) \\ Diterima: 26 Desember 2020/ Disetujui 1 Februari 2021
}

Cara sitasi: Aminarti, Ibrahim MN, Sadimantara MS. 2021. Analisis penggunaan rodhamin B pada produk terasi yang ada disekitar masyarakat Kecamatan Poleang Tengah Kabupaten Bombana, Sulawesi Tenggara. Jurnal Fish Protech. 4(1):2832.

\section{ABSTRACT}

This research was conducted by Descriptive method to obtain the required information. The way of data collection is by taking samples of shrimp paste in Kampung Baru Village (A), Lampopala Village (B), and Lauru Village (C) and then doing rodhamin $B$ dye testing on the three shrimp paste samples. The results of Analysis of Rodhamin B in shrimp paste Products around the Community of Central Poleang District Bombana regency, Southeast Sulawesi in Kampung Baru Village $(A)$, Lampopala Village $(B)$, and Lauru Village $(C)$ received negative results.

Keywords: qualitative analysis, rhodamin B, shrimp paste.

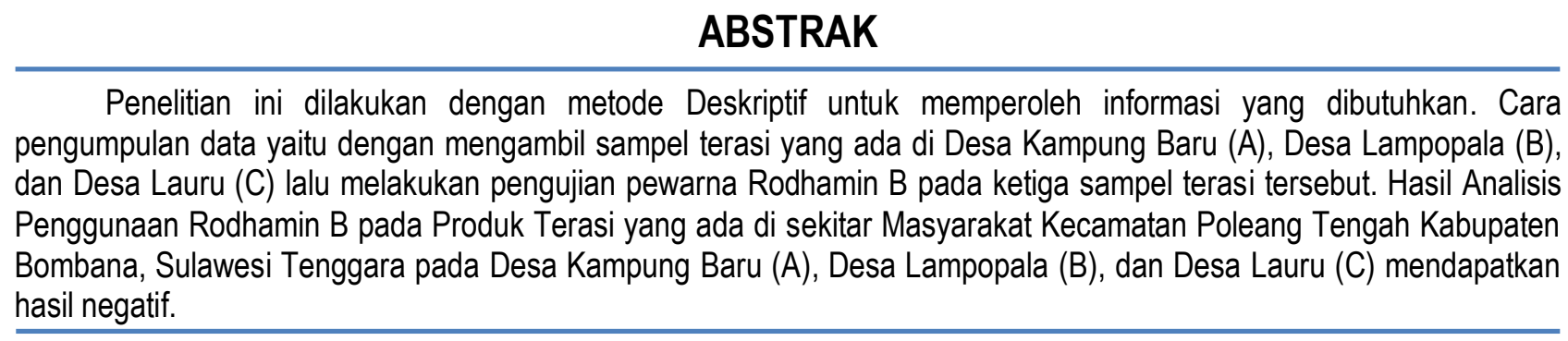

Kata kunci: analisis kualitatif, rhodamin B, terasi.

\section{PENDAHULUAN}

Kabupaten Bombana merupakan wilayah yang berada di Sulawesi Tenggara dan terkenal dengan terasi udangnya. Tempat yang terkenal dengan terasi udangnya yaitu di Desa Kampung Baru, Desa Lampopala dan Desa Lauru merupakan wilayah pesisir yang terkenal dengan penjualan terasi udangnya. Terasi udang merupakan salah satu produk unggulan di Kabupaten Bombana. Terasi yang terdapat di Desa Kampung Baru, Desa Lampopala dan Desa Lauru memiliki kekhasan tersendiri. Kemurnian warna maupun aroma membuat kesan tersendiri bagi calon konsumen. Warnanya yang coklat kehitam-hitaman, aroma udang rebon yang khas membuat produk ini memiliki kualitas tinggi. Harga terasi ini pun cukup terjangkau, harganya berkisar $\mathrm{Rp}$. 10.000 untuk mendapatkan satu biji terasi. Selain itu, 
warna pada terasi sangat penting untuk diperhatikan karena warna merupakan salah satu aspek dalam penerimaan konsumen terhadap suatu produk pangan. Tetapi untuk lebih menarik minat para konsumen, seringkali terasi diwarnai dengan warna yang mencolok menggunakan pewarna sintetik yang berbahaya bagi kesehatan. Menurut Sari et al,. (2009), sering terjadi penggunaan pewarna tambahan untuk bahan pangan, misalnya zat pewarna untuk tekstil dan kulit yang dipakai untuk mewarnai bahan pangan. Hal ini jelas sangat berbahaya bagi kesehatan karena ada residu logam berat pada zat pewarna tersebut. Zat pewarna sintetik yang dilarang penggunaannya dalam jumlah banyak dalam suatu produk pangan salah satunya adalah Rhodamin B (Wirasto, 2008).

Kelebihan dosis Rhodamin B bisa menyebabkan kanker, keracunan, iritasi paru-paru, mata, tenggorokan, hidung, dan usus. Masih adanya penggunaan zat berbahaya pada makanan karena efek yang ditimbulkan dari mengkonsumsi makanan tercemar tersebut tidak langsung seketika terasa. Penyakit akan timbul setelah beberapa tahun

\section{Alat dan Bahan}

Alat yang digunakan, yaitu : timbangan analitik, gelas ukur, batang pengaduk atau spatula, rak dan tabung reaksi, pipet tetes, pipet mikro, vortex, saring whatman, Spektrofotometri UV-Vis.

\section{Analisis Kualitatif Rhodamin B pada Terasi}

Analisis kualitatif dapat dilakukan untuk menyatakan ada tidaknya Rodhamin B dalam suatu bahan yang diuji dengan cara menambahkan pereaksi kimia (reagen) tertentu pada bahan yang diduga mengandung Rodhamin B sehingga dihasilkan suatu perubahan warna yang khas (Mahdi, 2016).

\section{HASIL DAN PEMBAHASAN}

Hasil

Penelitian ini bertujuan untuk mengidentifikasi dan menentukan kadar Rhodamin B pada terasi yang beredar disekitar Masyarakat Kecamatan Poleang Tengah Kabupaten Bombana, Sulawesi Tenggara. Sampel diperoleh dari 3 desa, yaitu Desa Kampung kemudian akibat residu yang mengendap dalam tubuh. Berbeda saat keracunan makanan karena kurang higienitas bisa terasa setelah mengkonsumsi suatu makanan. Di lapangan untuk makanan, Rhodamin B (warna merah) dan Metanil Yellow (kuning) sering dipakai mewarnai kerupuk, makanan ringan, terasi, kembang gula, sirup, biskuit, sosis, makaroni goreng, minuman ringan, cendol, manisan, gipang, dan ikan asap (Pohanish, 2008).

Hasil penelitian yang dilakukan oleh Santoso (2013) dari 6 sampel terasi yang diperoleh di pasar Kabupaten Cilacap terdapat 3 sampel dinyatakan positif mengandung Rhodamin $\mathrm{B}$. Hasil penelitian yang dilakukan oleh Astuti (2010) menemukan 70\% terasi di Desa Bonang Kecamatan Lasem Kabupaten Rembang mengandung Rhodamin B. Dari data tersebut menunjukkan bahwa penggunaan bahan tambahan pangan yang tidak diperbolehkan (Rhodamin B) masih dilakukan, sehingga hal ini dipandang menarik untuk dilakukan penelitian lebih lanjut, yaitu Identifikasi Penggunaan Zat Pewarna Rhodamin B pada Terasi.

Bahan yang digunakan, yaitu : terasi sebagai bahan utama yang akan diuji zat pewarnanya, Sampel (terasi), kit tester (tes kit Rhodamin B), HCL 10\%, $\mathrm{NaOH} 10 \%$, aquadest, tabung raksi, eter, dan bubuk Rhodamin B.

\section{Penetapan Kadar Rhodamin B pada Terasi.}

Penetapan kadar Rodhamin B dalam produk terasi dengan menggunakan spektrofotometer. Pengujian ini dilanjutkan apa bila sampel terasi yang diuji analisis kualitatif positif atau mengandung Rodhamin B (Mahdi, 2016).

Baru, Desa Lampopala, dan Desa Lauru. Setelah itu masing-masing sampel yang diambil dari tiga desa tersebut diberi kode A, B, dan C.

Untuk hasil uji laboratorium kandungan Zat Pewarna Rhodamin B pada terasi berdasarkan penelitian diketahui bahwa hasil Pemeriksaan kandungan Zat Pewarna Rhodamin B pada terasi 
yang ada di Kecamatan Poleang Tengah Kabupaten Bombana, Sulawesi Tenggara adalah negatif. Semua sampel yang digunakan sebanyak 3 sampel terasi $(A$, $B$, dan C), dapat dilihat pada Tabel 1 dibawah ini :

Tabel 1. Hasil Analisis Data Kualitatif Rhodamin B pada Terasi yang ada di Desa Kampung Baru (A), Desa Lampopala (B), dan Desa Lauru (C)

\begin{tabular}{|c|c|c|c|c|}
\hline No & Sumber Sampel & Kode & Reaksi Warna pada & Hasil Akhir \\
\hline & & Sampel & Lapisan atas Sampel & \\
\hline \multirow{7}{*}{1} & \multirow{7}{*}{ Desa Kampung Baru (A) } & $A_{1}$ & Tidak Mengalami & Negatif \\
\hline & & $A_{2}$ & $\begin{array}{l}\text { Perubahan Warna } \\
\text { (berwarna bening) } \\
\text { Tidak Mengalami }\end{array}$ & Negatif \\
\hline & & $A_{3}$ & $\begin{array}{l}\text { Perubahan Warna } \\
\text { (berwarna bening) }\end{array}$ & Negatif \\
\hline & & & Tidak Mengalami & \\
\hline & & & $\begin{array}{l}\text { Perubahan Warna } \\
\text { (berwarna bening) }\end{array}$ & \\
\hline & & $\mathrm{B}_{1}$ & Tidak Mengalami & Negatif \\
\hline & & $\mathrm{B}_{2}$ & $\begin{array}{l}\text { Perubahan Warna } \\
\text { (berwarna bening) }\end{array}$ & Negatif \\
\hline \multirow[t]{3}{*}{2} & \multirow[t]{3}{*}{ Desa Lampopala (B) } & & Tidak Mengalami & \\
\hline & & $\mathrm{B}_{3}$ & $\begin{array}{l}\text { Perubahan Warna } \\
\text { (berwarna bening) } \\
\text { Tidak Mengalami } \\
\text { Perubahan Warna } \\
\text { (berwarna bening) }\end{array}$ & Negatif \\
\hline & & $\mathrm{C}_{1}$ & $\begin{array}{l}\text { Tidak Mengalami } \\
\text { Perubahan Warna }\end{array}$ & Negatif \\
\hline \multirow[t]{2}{*}{3} & \multirow[t]{2}{*}{ Desa Lauru (C) } & $\mathrm{C}_{2}$ & $\begin{array}{l}\text { (berwarna bening) } \\
\text { Tidak Mengalami }\end{array}$ & Negatif \\
\hline & & $\mathrm{C}_{3}$ & $\begin{array}{l}\text { Perubahan Warna } \\
\text { (berwarna bening) } \\
\text { Tidak Mengalami } \\
\text { Perubahan Warna } \\
\text { (berwarna bening) }\end{array}$ & Negatif \\
\hline
\end{tabular}

\section{Pembahasan}

Hasil uji analisis pewarna Rhodamin B pada terasi menunjukkan bahwa kandungan Zat Pewarna Rhodamin $B$ pada sampel terasi yang diambil dari Desa Kampung Baru (A), Desa Lampopala (B), dan Desa Lauru (C) adalah negatif yang berarti dari semua sampel terasi yang diambil lalu diteliti di laboratorium tidak menggunakan zat pewarna Rhodamin B diketahui dengan ditandai tidak berubahnya warna (berwarna bening) pada sampel terasi. Hal ini sesuai dengan peraturan pemerintah RI No.28 tahun 2004 dan melalui Peraturan Menteri Kesehatan Indonesia (Permenkes) No.1168/Menkes/Per/X/1999, serta Undang-Undang keamanan Pangan yaitu UndangUndang Nomor 7 tahun 1996 yang menyatakan bahwa Rhodamin B merupakan salah satu bahan yang dilarang digunakan dalam kegiatan atau proses produksi pangan. Hasil penelitian ini juga 
memperlihatkan bahwa tingkat pengetahuan produsen terasi yang ada di Desa Kampung Baru (A), Desa Lampopala (B), dan Desa Lauru (C) dikatakan baik. $\mathrm{Hal}$ ini dikarenakan para produsen terasi menggunakan pewarna alami yang ada disekitar mereka. Selain aman untuk digunakan sebagai bahan tambahan pangan, bahan-bahan alami tersebut juga mudah untuk didapatkan oleh masyarakat yang ada di Desa Kampung Baru (A), Desa Lampopala (B), dan Desa Lauru (C).

Hasil penelitian yang lain tentang Rodhamin B pada sampel terasi yang ada di Kabupaten Cirebon dikatakan juga sangat baik. Memperlihatkan bahwa tingkat pengetahuan produsen tentang Rodhamin $B$ sangat baik. Untuk hasil uji laboratorium kandungan Zat Pewarna Rhodamin B pada terasi berdasarkan penelitian diketahui bahwa hasil Pemeriksaan kandungan zat pewarna Rhodamin B pada Terasi Produksi Cirebon adalah negatif. Semua sampel yang digunakan sebanyak 8 sampel Terasi $(A, B, C$, dan $D)$ yang masing-masingnya di ambil 2 sampel dan terbukti tidak mengandung Zat Pewarna Rhodamin B. Namun berbeda dari hasil penelitian yang dilakukan oleh Santoso (2013) dari 6 sampel terasi yang

\section{DAFTAR PUSTAKA}

Astuti, R.. 2010. Penggunaan Zat Pewarna Rhodamin B pada Terasi Berdasarkan Pengetahuan \& Sikap Produsen Terasi di Desa Bonang Kecamatan Lasem Kabupaten Rembang. Skripsi. Fakultas Kesehatan Masyarakat Universitas Muhammadiyah Semarang.

Direktotat Gizi Depkes, 1992. Produk fermentasi ikan garam. Balai Besar Riset Pengolahan Produk dan Bioteknologi Kelautan dan Perikanan.

Mahdi, C., 2016. Mengenal Berbagai Produk Reagen Kit Tester untuk Uji Formalin, Borak, Zat Pewarna Berbahaya dan Kandungan Yodium pada Garam Beryodium, Laboratorium Biokimia Universitas Brawijaya, Malang. diperoleh di pasar Kabupaten Cilacap terdapat 3 sampel dinyatakan positif mengandung Rhodamin B. Begitu juga dengan hasil penelitian yang dilakukan oleh Astuti et al., (2010) menemukan 70\% terasi di Desa Bonang Kecamatan Lasem Kabupaten Rembang mengandung Rhodamin B. Astuti, (2010), menyatakan bahwa sebagian besar produsen terasi tidak mengetahui tentang zat pewarna yang berbahaya dan menganggap bahwa Rhodamin B adalah pewarna untuk makanan dan mereka menggunakannya dalam terasi sebagai pewarna dengan alasan agar warna terasi lebih menarik. Produsen juga tidak mengetahui bahaya menambahkan Rhodamin B dalam makanan.

\section{KESIMPULAN}

Sampel terasi yang diambil di Desa Kampung Baru (A), Desa Lampopala (B), dan Desa Lauru (C) tidak mengandung pewarna sintesis atau pewarna Rodhamin B, hal ini ditandai dengan tidak mengalaminya perubahan warna ( tetap berwarna bening) pada sampel terasi yang telah diuji

Pohanish, R.. 2008. Sittig's handbook of toxic and hazardous chemicals and carcinogens. USA: Elsevier.

Sari, N. Edison, I. \& Sukirno, M. 2009. Kajian Tingkat Penerimaan Konsumen terhadap Produk Terasi Ikan dengan Penambahan Ekstrak Rosela. Berkala Perikanan Terubuk., 37(2): 91-103.

Santoso, HM. 2013. Analisis Kualitatif \& Kuantitatif Rhodamin B pada Terasi di Kabupaten Cilacap dengan Metode KLT. Fakultas Kedokteran dan IImu Farmasi Universitas Jendral Soedirman.

Suyatno. 2018. Modul Pelatihan Gizi Bagian Gizi Kesehatan Masyarakat Fakultas Kesehatan Masyarakat .Universitas Diponegoro, hal. 50-51S

Syahrin, A. 2016. Perbedaan Konsentrasi Garam terhadap Pembentukan WarnaTerasi

Udang Rebon (Acetessp.) Basah. Jurnal Pengolahan dan 
Bioteknologi Hasil Perikanan, 3(1), 2014.108-117.

Wirasto. 2008. Analisis Rhodamin B dan Methanil Yellow dalam Minuman Jajanan Anak di kecamatan Laweyan Kotamadya Surakarta dengan Metode Kromatografi LapisTipis. Skripsi pada Fakultas Farmasi Universitas Muhammadiyah Surakarta. 